\title{
Impaired Recognition of the Goal Location during Spatial Navigation in Rats with Hippocampal Lesions
}

\author{
Stig A. Hollup, Kirsten G. Kjelstrup, Joakim Hoff, May-Britt Moser, and Edvard I. Moser \\ Department of Psychology, Norwegian University of Science and Technology, 7491 Trondheim, Norway
}

Converging evidence suggests that the hippocampus is essential for goal-directed spatial navigation. Successful navigation requires not only the ability to compute an appropriate path toward the target but is also guided by recognition of places along the trajectory between start and goal. To determine whether the hippocampus contributes to place recognition, we trained rats with hippocampal lesions in an annular water maze with a remotely controlled escape platform at a constant location in the corridor. The platform remained submerged and unavailable until the rat had swum at least one full lap. Probe trials with the platform unavailable for $60 \mathrm{sec}$ were inserted at regular intervals. In these trials, the rat would swim over the platform several times, regardless of its navigational abilities. After a few training sessions, all sham-operated control animals

Although the hippocampus is involved in a broad range of memory types (Squire, 1992), it appears to have a particular function in spatial navigation and memory (O'Keefe and Nadel, 1978; Nadel, 1991; Steckler et al., 1998). First, there is a strong activation of the hippocampus during memory-guided spatial navigation (Maguire et al., 1997, 1998; Bontempi et al., 1999). Second, activity in hippocampal pyramidal neurons is location-specific (O'Keefe and Dostrovsky, 1971; Wilson and McNaughton, 1993), depends on the configuration of distal landmarks (Muller et al., 1987; O'Keefe and Speakman, 1987; O'Keefe and Burgess, 1996), and may outlast removal or concealment of the controlling cues (O'Keefe and Speakman, 1987; Quirk et al., 1990). Finally, animals with hippocampal lesions fail to learn the location of a hidden goal whose position is defined by the arrangement of distal landmarks (Jarrard, 1978; Olton et al., 1978; Morris et al., 1982, 1990; Sutherland et al., 1983).

However, not all features of spatial navigation and memory depend on the hippocampus. Rats with hippocampal lesions can solve landmark-based navigation tasks under certain conditions, such as when training is prolonged (Morris et al., 1990) or when task difficulty is increased progressively (Whishaw et al., 1995; Whishaw and Jarrard, 1996). To identify the exact function of the hippocampus in spatial navigation, it would be helpful to isolate navigational operations experimentally.

Received Dec. 13, 2000; revised Feb. 16, 2001; accepted April 3, 2001.

This work was supported by Norwegian Research Council Grants 122512/310 and 133958/420 and Fifth Framework Research, Technological Development, and Demonstration Programme of the European Commission Grant QLG3-CT-1999-00192. We thank Dr. R. Biegler for helpful comments and discussion, and K. Barmen, R. Dahl, I. Hammer, and K. Haugen for technical assistance.

Correspondence should be addressed to Edvard Moser, Department of Psychology, Norwegian University of Science and Technology, N-7491 Trondheim, Norway. E-mail: edvard.moser@svt.ntnu.no.

Copyright (C) 2001 Society for Neuroscience $\quad 0270-6474 / 01 / 214505-09 \$ 15.00 / 0$ reduced their swim velocity when they approached the platform, indicating that they recognized the target location. Rats with hippocampal lesions, in contrast, swam at the same velocity as elsewhere in the corridor. Preoperative training or prolonged postoperative training did not alleviate the deficit. Rats with hippocampal lesions were able to learn a cued version of the task, which implies that the failure to slow down was not attributable to motor inflexibility. Thus, hippocampal lesions caused a severe but selective deficit in the identification of a location, suggesting that the hippocampus may be essential for image recognition during spatial navigation.

Key words: hippocampus; learning; memory; recognition; spatial; navigation; trajectory; plasticity; rat

Goal-directed navigation may involve several different algorithms in succession (Cheng, 2000), and each algorithm may involve several successive operations. Recognition of the current location is one such operation, but it plays different roles in different proposed algorithms. In some models, recognition of the current location is a first and necessary step in deciding what to do next (Benhamou et al., 1995; Brown and Sharp, 1995; Reid and Staddon, 1998). What these models have in common is that recognition or recall of a location is a separate step from choosing where to go next, and these operations could therefore be mediated by different neuronal circuits.

Because some types of recognition memory are likely to be independent of the hippocampus (Murray and Mishkin, 1998; Brown and Aggleton, 2001), we examined whether the integrity of this structure is necessary for image recognition during navigation when the goal can be reached without the use of a geometric algorithm for path calculation. Annular place navigation tasks (O'Keefe et al., 1975) can be used for this purpose. Rats with or without hippocampal lesions were trained to swim in laps in an annular corridor in a water maze with a hidden escape platform at a fixed location in the corridor. On probe trials without the platform, normal rats exhibited reduced speed each time they passed the target position, indicating that they recognized the place. The corridor walls guided all animals to the goal, so a failure to slow down at the target after a lesion of the hippocampus might imply a specific deficit in recognition of locations.

\section{MATERIALS AND METHODS}

Subjects. Fifty-seven male Long-Evans rats (350-500 gm) were housed in groups of four to six in large transparent polycarbonate cages $(59 \times 38 \times$ $20 \mathrm{~cm}$ ). The animals were kept on a $12 \mathrm{hr}$ light/dark schedule and tested in their dark phase. Animals with lesions received food and water ad libitum.

Lesions. The rats were anesthetized with Equithesin (pentobarbital 
and chloral hydrate; $1.0 \mathrm{ml} / 250 \mathrm{gm}$ body weight, i.p.). Hippocampal lesions were made by bilateral injection of ibotenic acid (Biosearch Technologies, San Rafael, CA) at 28 sites (Jarrard, 1989). Ibotenic acid was dissolved in PBS, pH 7.4, at $10 \mathrm{mg} / \mathrm{ml}$ and injected with a $1 \mu \mathrm{l}$ Hamilton syringe mounted to the stereotaxic frame. Injections of $0.05-$ $0.10 \mu \mathrm{l}$ were made over $10-20 \mathrm{sec}$ at each site. The syringe was retracted 2 min after the injection. In sham-operated rats, the syringe was lowered through the neocortex, but no drug was infused.

Annular water maze task. The animals were trained to search for a hidden platform in an annular corridor in a white circular polyvinyl chloride tank (198 cm diameter and $50 \mathrm{~cm}$ deep) filled to a depth of 40 $\mathrm{cm}$ with water at $25 \pm 2^{\circ} \mathrm{C}$ (Fig. 1). The water was made opaque with latex liquid. The corridor was defined by two circular, transparent Perspex walls of 75 and $95 \mathrm{~cm}$ diameter, respectively, placed around the center of the water-filled tank. The tank contained four pneumatically controlled $10-\mathrm{cm}$-diameter escape platforms, one in the center of each pool quadrant and all within the corridor. Each platform could be regulated between an available and an unavailable level $(1.5$ and $22 \mathrm{~cm}$ below the surface, respectively). Only one platform was used at a time; the other three remained submerged at the bottom of the tank. For each rat, the location of the active platform was constant throughout the experiment. The apparatus was located in a room $(4 \times 7 \mathrm{~m})$ with multiple cues on all sides. A wall $(2 \times 2 \mathrm{~m})$ separated the pool from the experimenter during the trials.

All training sessions consisted of four consecutive trials. In each trial, the rats were released from one of four equally spaced start positions along the perimeter of the corridor in a predetermined and pseudorandom order. Trials in the corridor always started with the platform in the submerged (unavailable) position. The platform was not raised until the rat had swum at least one full lap in the corridor. In this way, the rats learned to circle through the corridor rather than floating at the expected platform location. If the rats had not entered the platform after $120 \mathrm{sec}$, they were guided onto it. Every fourth trial was a probe trial. In these trials, the platform was kept in its lower position for the first $60 \mathrm{sec}$ of the test, and the search pattern was recorded. The platform was subsequently raised to its upper, accessible position, after which the rat found the platform. The rats were released from the quadrant opposite to the platform on the probe trials. The position of the rat was revealed by a video tracking system (Axona Ltd., St. Albans, UK) that extracted and stored the $x--y$ coordinates of the rat's black head on the white pool surface (in the water maze) at $50 \mathrm{~Hz}$. After swimming, the rat was placed under an infrared heating lamp.

New learning in pretrained animals. There were three training conditions in the annular task. First, 10 rats with hippocampal lesions and 10 with sham lesions received 40 trials of pretraining with a constant platform location in a different water tank. There was no corridor during this pretraining. New learning in these animals was tested on a single day consisting of 13 trials. These trials were given as three blocks of four trials, each starting with a probe trial, plus a final probe trial at the end. The interval between successive blocks of trials was $30 \mathrm{~min}$. During the probe trials, the platform was raised at $60 \mathrm{sec}$.

Learning in naïve animals. A second group of animals (six with intended hippocampal lesions and 6 with sham lesions) received no pretraining. Training in the corridor was conducted over a period of $8 \mathrm{~d}$. On each of days $1-3$ and $6-8$, the animals received four blocks of training with the hidden platform in a constant position, according to the same protocol as in the pretrained rats (13 trials). On days 4 and 5, the platform was made visible. The pneumatically controlled platforms were all submerged. A $10-\mathrm{cm}$-long split was made in the inner corridor wall, and a new, elevated platform was placed $10 \mathrm{~cm}$ behind the split. The platform disk was marked with colored tape and reached $1.5 \mathrm{~cm}$ above the water surface. Each day, the animals received two blocks of four trials, and the latency to swim through the split and climb the platform was recorded. On days $6-8$, the inner corridor wall was replaced, and the original training procedure was resumed.

Retention. Finally, a third group of animals was trained for $5 \mathrm{~d}$ in the corridor before surgery. All animals received 10 blocks of four trials, with two blocks of training each day. A probe test was conducted on the sixth day. The platform was raised at the end of this trial, as above. The animals were ranked, matched, and assigned to surgery groups according to the proportion of time they spent around the platform. Surgery (nine hippocampal lesions and eight sham lesions) was conducted after the probe trial. Six days later, a single retention test was conducted. Again, the platform was kept in its lower position for the first $60 \mathrm{sec}$, and the animal's position was tracked.
Analysis of corridor behavior. For analysis of behavior in the corridor task, the water maze was divided into 12 segments of $30^{\circ}$ arc with fixed segment borders. The platform was in the center of one of the segments. Memory was expressed as a consistent reduction of swim velocity within the segment that contained the platform compared with the other sectors, as well as a corresponding increase in time spent in this segment and an increase in the tortuosity of the swim trajectory at this location. To estimate tortuosity, we divided the swim path into segments of $0.5 \mathrm{sec}$ and expressed the length of each path segment as a percentage of the shortest possible path between the start and the end point of the segment. The average value was referred to as "path efficiency."

Delayed-nonmatching-to-sample task. Eight animals (four hippocampal and four sham) were trained in a nonspatial delayed-nonmatching-tosample task in the same water maze as above. The whole water maze arena was used for this purpose. White curtains were drawn around the rim of the pool to mask external landmarks, and the cues were objects hanging in thin, white string $10-15 \mathrm{~cm}$ over the water surface. Training consisted of 107 sessions, distributed over $11 \mathrm{~d}$ (seven on day 1 and then 10 per day). Each session consisted of a sample trial and a test trial $1 \mathrm{~min}$ later. On the sample trial, a distinct cue was hanging over the pool. The rat swam freely and was picked up after $30 \mathrm{sec}$. On the subsequent test trial, two platforms were made available. The cue from the sample trial was attached above one of the platforms, whereas a different and new cue signaled the other platform. The rat was released from the rim of the pool opposite to the platforms. If the rat entered the platform beneath the familiar cue, both platforms were immersed and the animal was left in the water for another $30 \mathrm{sec}$. If the rat swam to the new cue, the platform remained elevated. We used a collection of 214 cue objects with distinct shape, brightness, and color (5-10 cm large, e.g., a coil of wire, a cup, a plate, a thermometer, a balloon, a can, and a bottle). The cue locations were always different in sample and test trial and were varied according to a pseudorandom schedule. New pairs were used in each trial. For each pair, the designation of sample and novel object was random. The rats had been used in a contextual conditioning experiment during the preceding week.

Histology. The rats received an overdose of Equithesin and were perfused transcardially with saline, followed by $4 \%$ formaldehyde. The brains were extracted and stored in $4 \%$ formaldehyde. At least 1 week later, the brains were quickly frozen, cut in coronal sections $(30 \mu \mathrm{m})$, mounted, and stained with cresyl violet. Every 10th section in the area of the hippocampus and the subiculum was retained. The volume of residual hippocampal tissue in the lesioned animals was determined by placing each section under a microscope attached to a digital camera (Olympus DP10; Olympus Optical, Tokyo, Japan) and a personal computer, taking the images into Canvas 7.0 (Deneba Systems, Miami, FL), tracing an outline of remaining hippocampal tissue, and determining the area of the outlined region for each section (Moser and Moser, 1998). The volume of the hippocampal remnant was expressed as the percentage of the mean volume of hippocampal tissue in the sham-operated group.

Approvals. The experiments were approved by the National Animal Research Authority of Norway.

\section{RESULTS}

\section{Hippocampal lesions}

The hippocampal damage was nearly complete in all animals that received ibotenic acid injections (Fig. 1), except in one rat that had no damage in the hippocampus beyond the cannula tracks. The latter animal was assigned to the sham group. The volume of the tissue remnants in the remaining hippocampal animals ranged from 0.9 to $46.0 \%$ of total hippocampal volume, with a mean \pm SEM of $10.6 \pm 2.5 \%$. The remnants were mainly located in the ventral hippocampus. The lesions extended into the adjacent subiculum in most rats in the hippocampal group. Subicular damage was mainly seen on sections close to the hippocampus and mainly in the ventral part of the structure. No animals were excluded.

\section{Experiment 1: learning in pretrained animals}

Recognition of the goal location was examined in pretrained animals that received new training in an unfamiliar environment. At the start of the new training, neither the lesion group nor the 

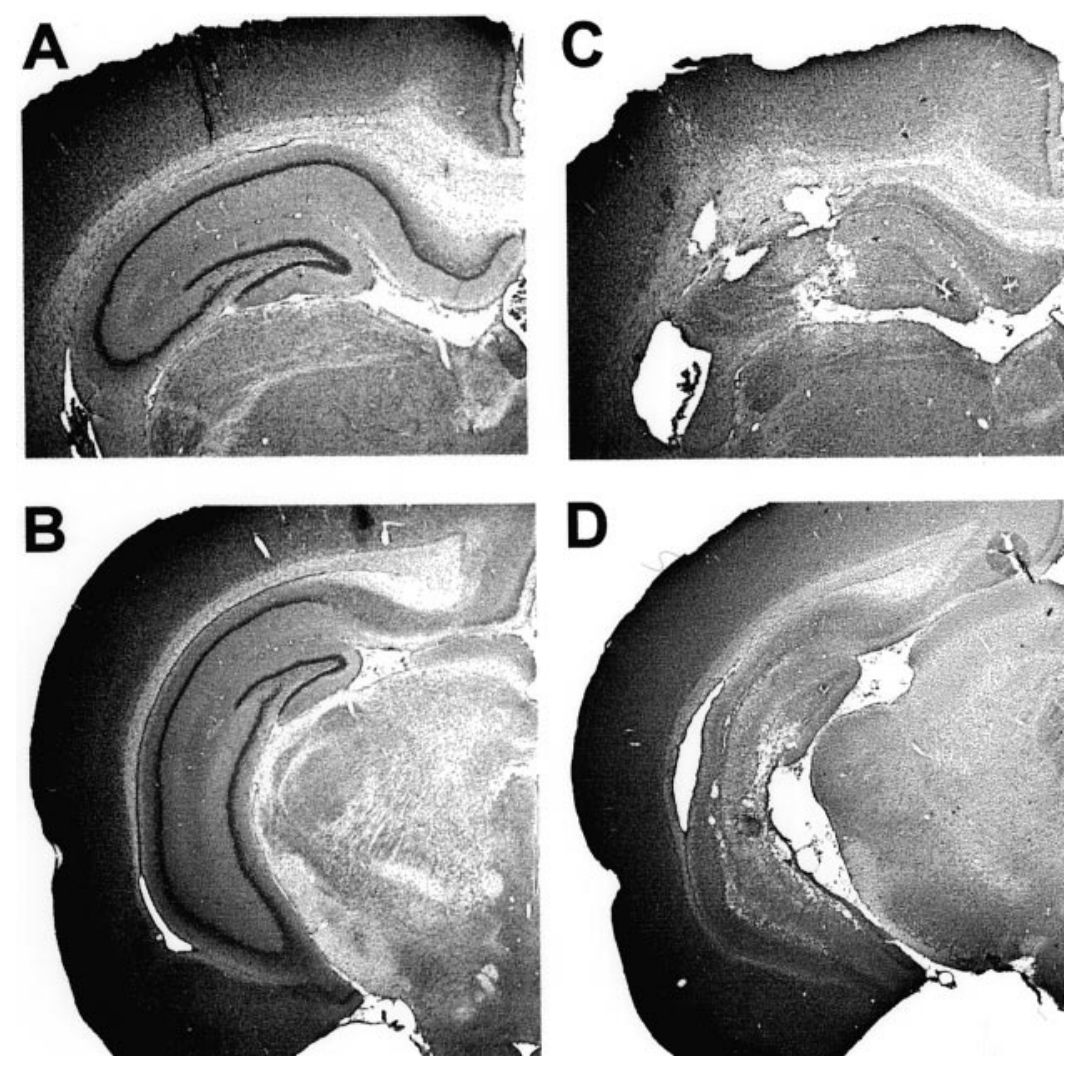

Figure 1. Coronal sections showing cresyl violet stains of neuronal cell bodies in the dorsal $(A, B)$ and intermediateto-ventral $(C, D)$ hippocampus of a sham-operated rat $(A, C)$ and a rat with a complete hippocampal lesion $(B, D)$. In the latter animal, $2.5 \%$ of hippocampal volume was spared.
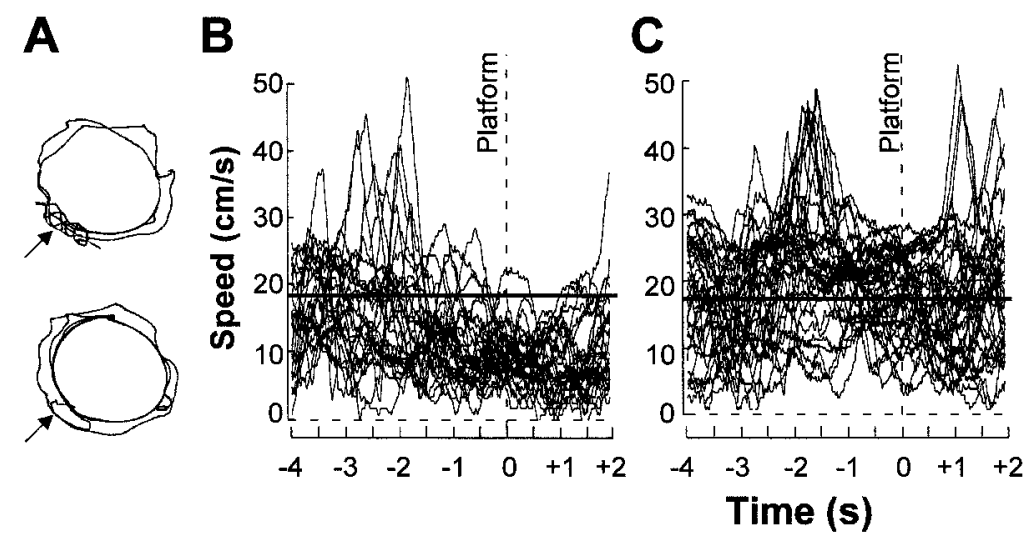

Figure 2. Swim pattern at the goal position on the final probe trial. $A$, Trajectory of a sham-operated rat (top) and a rat with a complete hippocampal lesion (HPC; bottom). Arrows indicate platform position on preceding training trials. $B$, Swim velocity during every single passage over the platform in all 10 sham-operated control animals (total of 30 passages; each curve corresponds to 1 passage). The crossing of the center of the platform segment was defined as $t=0 \mathrm{sec}$ (stippled vertical line). The horizontal line indicates the average swim velocity of the group outside the platform segment (330 of arc). The sham-operated animals consistently slowed down when they approached the platform area. $C$, Swim velocity for every single passage over the platform in all 10 hippocampal-lesioned animals (total of 39 passages; horizontal line indicates average swim velocity outside the platform segment). The swim velocity over the platform was not lower than in other parts of the corridor.

sham group showed any preference for the platform segment of the water maze corridor. As training continued, the shamoperated animals frequently speeded up when approaching the platform and then always slowed down as they passed over the target on the probe trials (Fig. 2). The time spent at the expected target location increased gradually (Figs. 3, 4), indicating that these animals recognized the place as the goal location. They showed no change in behavior outside the platform region. Rats with hippocampal lesions, in contrast, failed to spend any more time at the platform position than in other segments (Figs. 3, 4). Occasionally, some of them increased their speed 1-2 sec before reaching the target position, but they nonetheless failed to slow down when they arrived at the destination (Fig. 2C).

We compared performance in two segments of the corridor, one consisting of the $30^{\circ}$ of arc around the platform and the other consisting of the remaining $330^{\circ}$. A repeated-measures ANOVA of behavior in these segments showed significant effects of groups $\times$ segments (speed, $F_{(1,54)}=6.6, p<0.05$; dwell time, $\left.F_{(1,54)}=29.0, p<0.001\right)$ and groups $\times$ segments $\times$ trials (speed, $F_{(3,54)}=3.4, p<0.05$; dwell time, $\left.F_{(3,54)}=5.8, p<0.005\right)$. A separate analysis dealing with all $1230^{\circ}$ segments on the final probe test revealed significant groups $\times$ segments effects on speed 


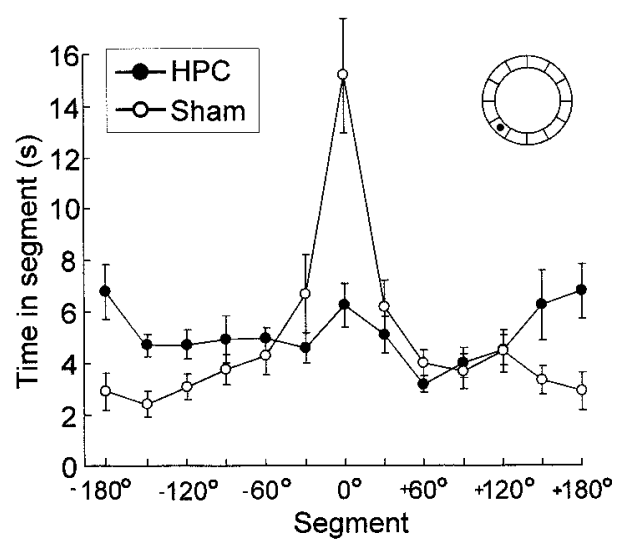

Figure 3. Dwell time (means \pm SEM) in each of $1230^{\circ}$ segments of the annular corridor (inset) in the final probe trial in the pretrained animals. The platform segment is defined as $0^{\circ}$. Sham-operated rats, but not rats with hippocampal lesions $(H P C)$, spent more time in the platform segment than in other segments.

$\left(F_{(11,198)}=2.3, p=0.01\right)$ and time $\left(F_{(11,198)}=6.3, p<0.001\right)$, with a significant group difference in the target segment (speed, $t_{(18)}=4.7, p<0.001$; time, $t_{(18)}=3.7, p=0.001$; one-tailed Student's $t$ tests). There was no significant main effect of groups on speed $\left(F_{(1,18)}=2.8, p>0.10\right)$. On the final probe test, the average speed of swimming outside the target segment was $20.2 \pm$ $1.4 \mathrm{~cm} / \mathrm{sec}$ in the hippocampal group and $18.1 \pm 0.6 \mathrm{~cm} / \mathrm{sec}$ in the sham group (Fig. 4).

Recognition of the goal location was also expressed as an increase in the deviation of the swim path from the shortest possible trajectory through the segment (path efficiency). Path lengths in the target segment increased with training in the sham-operated group but not in animals with hippocampal lesions (groups $\times$ trials, $F_{(3,54)}=4.6, p<0.005$; groups $\times$ segments $\times$ trials, $\left.F_{(3,42)}=4.2, p=0.01\right)$ (Fig. $4 C$ ).

There was no significant correlation between the volume of residual hippocampal tissue and performance on the final probe test (dwell time, $r=0.22$; speed, $r=-0.08$; path efficiency, $r=$ 0.08 ; all $p>0.50)$.

\section{Experiment 2: learning in naïve animals}

We subsequently trained a group of naïve rats with hippocampal lesions or sham lesions in the annular water maze. Neither the sham group nor the hippocampal group exhibited any preference for the platform region on the initial trial (swim velocity in the platform segment, $20.4 \pm 2.4$ and $17.4 \pm 0.9 \mathrm{~cm} / \mathrm{sec}$, respectively) (Fig. 5). As early as the second probe test, however, the sham animals began to reduce the speed as they passed over the platform and spent more time at this location. Rats with hippocampal lesions showed no change in speed at the target position, and at the end of the training (trial 39), there was a clear group difference (sham, $12.5 \pm 0.7 \mathrm{~cm} / \mathrm{sec}$; hippocampal, $20.1 \pm$ $\left.2.0 \mathrm{~cm} / \mathrm{sec} ; t_{(10)}=4.0 ; p<0.005\right)$. As in the pretrained animals, there was no systematic change in speed outside the platform segment. In the sham group, the average velocity in the nontarget regions increased from $18.9 \pm 0.5$ to $20.0 \pm 0.9 \mathrm{~cm} / \mathrm{sec}$; in the hippocampal group, it increased from $18.9 \pm 1.4$ to $21.6 \pm 1.1$ $\mathrm{cm} / \mathrm{sec}$. A repeated-measures ANOVA of swim velocity in the target $\left(30^{\circ}\right)$ and nontarget $\left(330^{\circ}\right)$ segments showed a significant groups effect $\left(F_{(1,10)}=16.6, p<0.005\right)$, but this was accompanied by significant effects of groups $\times$ segments $\left(F_{(1,110)}=10.2, p<\right.$ $0.01)$ and groups $\times$ segments $\times$ trials $\left(F_{(11,110)}=2.6, p<0.01\right)$.
Thus, the rats swam slower in the target than the nontarget segments, but the difference was expressed only in the control animals (Fig. 5).

The distribution of dwell time changed in a similar manner. On the initial trial, neither the sham group nor the hippocampal group spent more time in the platform segment than expected by chance $(4.4 \pm 0.5$ and $5.4 \pm 1.0 \mathrm{sec}$, respectively; chance level, 5.0 $\mathrm{sec})$. On the final trial, the sham group spent $10.5 \pm 0.8 \mathrm{sec}$ in the target segment, whereas the hippocampal group still performed at chance $\left(6.3 \pm 1.4 \mathrm{sec} ; t_{(10)}=2.9 ; p<0.01\right)$. An ANOVA of dwell time in the goal segment $\left(30^{\circ}\right)$ and in the other segments $\left(330^{\circ}\right)$ showed significant effects of groups $\times$ segments $\left(F_{(1,110)}=18.3\right.$, $p<0.005)$ and groups $\times$ segments $\times$ trials $\left(F_{(11,110)}=1.9, p=\right.$ $0.05)$.

Finally, the hippocampal lesions affected the tortuosity of the swim trajectories. As training proceeded, paths in the goal segment became increasingly less direct in the sham group but exhibited no change in the hippocampal group. On the first probe trial, there was no significant group difference (path efficiency of $86.2 \pm 2.3$ and $89.0 \pm 1.0 \%$, respectively). On the final probe test (trial 39), the path efficiency in the sham group was $79.8 \pm 1.0 \%$ in the target segment compared with $89.1 \pm 1.0 \%$ in the nontarget segments $\left(t_{(6)}=6.1, p<0.001\right)$. There was no difference between target and nontarget segments in the hippocampal group (89.8 \pm 2.5 and $91.4 \pm 1.1 \%$, respectively). An overall analysis on the entire set of probe trials showed significant effects of groups $\left(F_{(1,10)}=40.1, p<0.001\right)$, groups $\times$ segments $\left(F_{(1,110)}=6.1, p<\right.$ $0.05)$, and groups $\times$ segments $\times$ trials $\left(F_{(11,110)}=2.7, p<0.005\right)$.

\section{Cued navigation}

It is conceivable that hippocampal-lesioned animals failed to slow down over the platform because of general hyperactivity or an inability to change between motor programs. On the fourth and fifth days of training, we therefore tested the above animals in a cued version of the corridor task. No platforms were available inside the corridor in this condition. Instead, a 10-cm-long split was made in the inner corridor wall, and a new, clearly visible platform was placed $10 \mathrm{~cm}$ behind the split (Fig. 6). Both shamoperated and hippocampal-lesioned animals learned to escape onto the visible platform. The hippocampal group was slower to climb the platform on the first session, but the escape latencies were soon below $10 \mathrm{sec}$ in both groups. On the final (fourth) session, the latencies were $6.7 \pm 0.6$ (hippocampal) and $4.3 \pm 0.2$ (sham) sec. Although the group difference was small, it was significant $\left(F_{(1,10)}=7.8, p<0.05\right)$. The difference was attributable to a few trials in which the hippocampal animals ignored the split in the inner corridor wall. During these trials, the rats were always swimming along the outer corridor wall when they passed. Trajectories in the middle or inner part of the corridor were followed by turning and subsequent escape. These observations exclude motivational and motor explanations of why hippocampal-lesioned animals failed to slow down in the platform segment.

\section{Extended training}

To determine whether rats with hippocampal lesions are able to overcome their recognition deficit with extended training, we trained the above animals for another $3 \mathrm{~d}$ (39 trials). The original inner corridor wall was reintroduced, and four blocks of trials were run each day.

There was no significant improvement in the performance of the hippocampal group (Fig. 5). The average swim velocity in this 


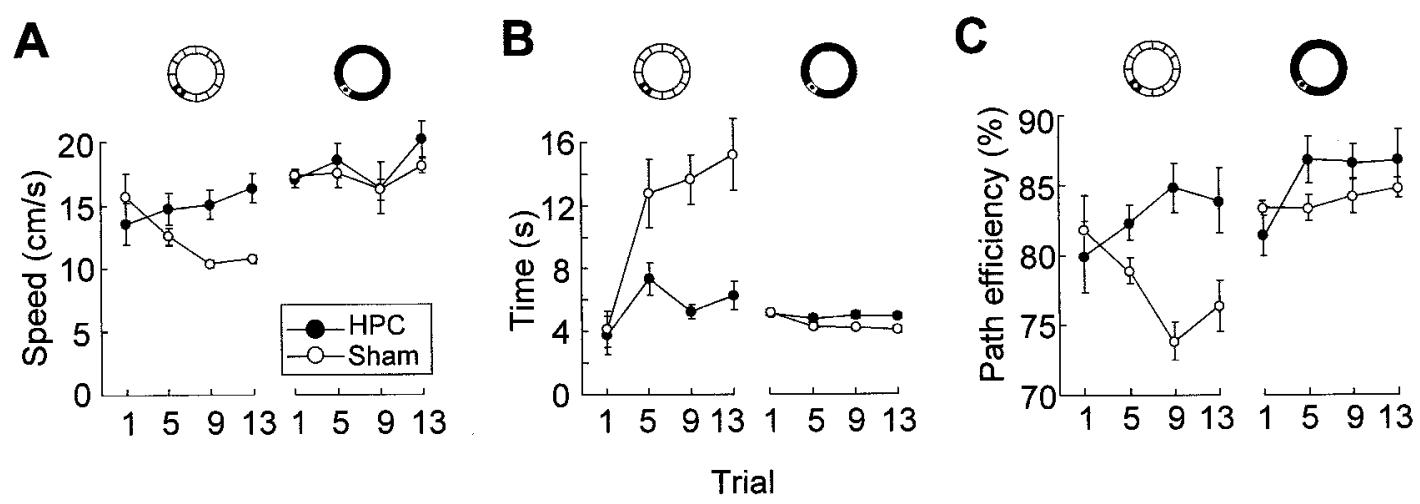

Figure 4. Development of swim speed $(A)$, dwell time $(B)$, and path efficiency $(C)$ inside the platform segment $\left(30^{\circ}\right.$; left column $)$ and outside this segment (remaining $330^{\circ}$; right column) across four probe tests (means \pm SEM; pretrained animals). Rats with hippocampal lesions $(H P C)$ failed to slow down $(A)$, spend more time $(B)$, or make more circuitous swim paths $(C)$ in the platform segment.

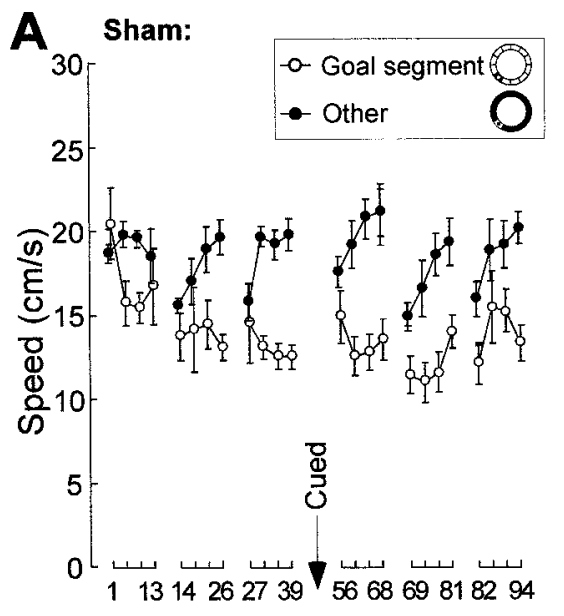

Figure 5. Effect of extended training with the hidden platform in naïve rats with hippocampal lesions or sham surgery. The diagrams show the development of swimming speed (means $\pm \mathrm{SEM})$ in the platform segment $\left(30^{\circ}\right.$ of arc; inset) and the nontarget segments $\left(330^{\circ}\right.$ of arc). $A$, Shamoperated rats. $B$, Rats with hippocampal lesions $(H P C)$. Note that the hippocampal group failed to slow down in the platform segment and that prolonged training did not improve performance in these animals. The training was interrupted by two cued training sessions (trials $40-55$ ). group was not lower in the platform segment $(20.6 \pm 2.4 \mathrm{~cm} / \mathrm{sec})$ than in other segments $(21.7 \pm 1.2 \mathrm{~cm} / \mathrm{sec})$, nor was there any increase in dwell time in the target zone $(6.3 \pm 0.9 \mathrm{sec}$; chance level, $5.0 \mathrm{sec}$ ). The mean path efficiency in the target segment was $87.3 \pm 1.7 \%$ compared with $89.7 \pm 1.4 \%$ in the nontarget segments. The sham-operated animals maintained their strong preference for the platform segment, as demonstrated by slower swimming, longer dwell time, and more circuitous swim paths in the platform segment (average speed, $13.2 \pm 0.7 \mathrm{~cm} / \mathrm{sec}$; average dwell time, $9.3 \pm 0.7 \mathrm{sec}$; average path efficiency, $80.2 \pm 1.3 \%$ ).

An ANOVA of behavior in target and nontarget segments on trials 56-94 showed a significant effect of groups on speed $\left(F_{(1,10)}\right.$ $=14.0, p<0.005)$ and path efficiency $\left(F_{(1,10)}=40.1, p<0.001\right)$ but also a significant groups $\times$ segments interaction effect (speed, $F_{(1,110)}=5.1, p<0.05$; dwell time, $F_{(1,110)}=7.3, p<0.05$; path efficiency, $\left.F_{(1,110)}=6.1, p<0.05\right)$. There was no effect of segments $\times$ trials $(F<1)$ or groups $\times$ segments $\times$ trials $\left(F_{(11,110)}\right.$ $=1.3$ ) on dwell time, but the effects on speed (segments $\times$ trials, $F_{(11,110)}=2.6, p<0.005$; groups $\times$ segments $\times$ trials, $F_{(11,110)}=$ 2.6, $p<0.005)$ and path efficiency (segments $\times$ trials, $F_{(11,110)}=$ $4.4, p<0.001$; groups $\times$ segments $\times$ trials, $F_{(11,110)}=2.7, p<$ $0.005)$ were significant. The latter effects did not reflect a systematic change toward low speed and circuitous paths in the goal segment but could be caused by the less selective behavior of the sham group on the first trial of each day (Fig. 5).

\section{Experiment 3: retention}

To determine whether the hippocampus is essential for goal recognition also when the task is acquired by an intact hippocampus, we examined the effect of hippocampal lesions on retention in 17 rats that had been trained preoperatively for $5 \mathrm{~d}$ (40 trials) in the annular water maze. During pretraining, all of these rats searched for the hidden platform in the correct segment. On the final probe test, the animals spent significantly more time in the platform segment than elsewhere in the corridor $\left(t_{(16)}=4.1, p<\right.$ 0.001; one-tailed Student's $t$ test) (Fig. 7A). They swam slower and with less direct paths in the platform segment than in the other segments (speed, $t_{(16)}=4.5, p<0.001$; path efficiency, $t_{(16)}=2.7$, $p<0.01)$. The animals were ranked according to time spent in the platform zone, matched, and assigned to two groups, which received hippocampal lesions and sham surgery, respectively. There was no group difference on any measure after the matching (group and group $\times$ segment, all $F<1$ ). Surgery started $1 \mathrm{hr}$ after the probe test.

Retrieval was measured on a second probe test $6 \mathrm{~d}$ later. Only the sham-operated group maintained its preference for the platform segment (Fig. 7). The performance of the sham group was as accurate as on the preoperative test 1 week earlier. Rats with hippocampal lesions, in contrast, failed to slow down at the platform and spent no more time there than elsewhere. A repeated-measures ANOVA of behavior in target and nontarget 


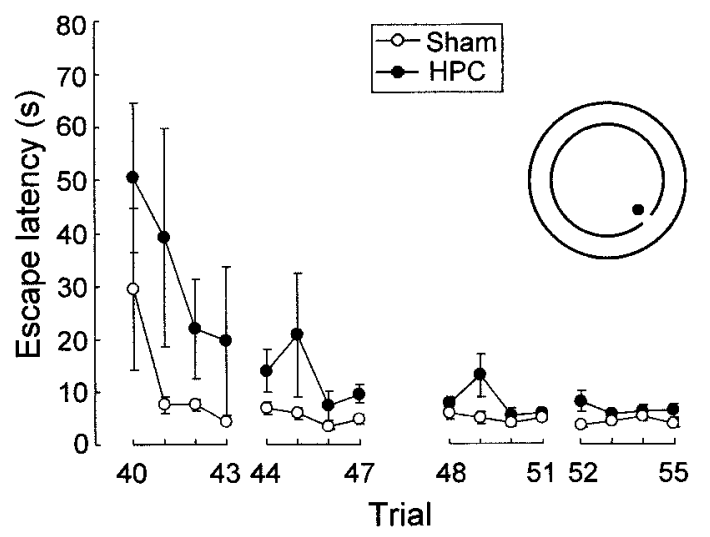

Figure 6. Latency to climb the platform in a cued version of the task (means \pm SEM). A clearly marked platform was elevated above the water surface but was placed behind the inner corridor wall (inset). A $10-\mathrm{cm}-$ long split in the inner corridor wall allowed the rat to access the platform. Both sham-operated and hippocampal-lesioned (HPC) animals learned to find and enter the visible platform within a few seconds after they were released into the corridor.

segments showed a significant effect of groups on swim velocity $\left.F_{(1,15)}=20.1, p<0.001\right)$ and path efficiency $\left(F_{(1,15)}=33.5, p<\right.$ $0.001)$, indicating faster swimming and less circuitous trajectories in the hippocampal group. There was also a significant groups $\times$ segments effect on time $\left(F_{(1,15)}=6.1, p<0.05\right)$ and path efficiency $\left(F_{(1,15)}=5.4, p<0.05\right)$. The groups $\times$ segments effect on speed was not significant $\left(F_{(1,15)}=1.6\right)$, possibly because of the large general increase in swim velocity in the hippocampal group in this specific experiment. The correlation between the volume of residual hippocampal tissue and behavior in the platform segment on the retention test was not significant (dwell time, $r=$ -0.43 ; speed, $r=0.50$; path efficiency, $r=-0.57$; all $p>0.10$ ).

Altogether, the data suggest that hippocampal lesions disrupted recognition of the goal location also when the task was acquired with an intact brain. Although retention was tested only $6 \mathrm{~d}$ after surgery, the deficit was probably specific. Previous research has shown that, $7 \mathrm{~d}$ after surgery, animals with partial hippocampal lesions can acquire a new spatial task within one or a few trials, at the same rate as the control animals, even if their retention of previous spatial memory is totally disrupted (Moser and Moser, 1998).

\section{Experiment 4: single-item recognition}

To examine the functional specificity of the recognition deficit in the spatial task, we tested nonspatial recognition of single items in the water maze in eight rats with sham lesions or hippocampal lesions. We used a nonspatial delayed nonmatching procedure and determined whether such animals could distinguish nonfamiliar items from items that had been presented on a sample trial 1 min earlier. All animals swam directly to one of the cues during the choice trial. There was no initial preference for the nonfamiliar cue (sham group, $50.0 \pm 4.1 \%$; hippocampal group, $42.9 \pm$ $14.3 \%$ ). Both sham-operated and hippocampal-lesioned animals gradually began to swim more often to the novel cue, although their preference for the new object was still only moderate at the end of the training. On the last $2 \mathrm{~d}, 63.8 \pm 2.4 \%$ of the shamoperated animals and $68.8 \pm 7.2 \%$ of the hippocampal-lesioned animals preferred the nonfamiliar cue, which was better than chance $\left(t_{(7)}=4.5, p<0.005\right)$. There were no group differences (effects of groups and groups $\times$ sessions, $F<1$ ). However, choices were slightly more consistent in the sham group (9 of 10 last sessions above chance) than in the hippocampal group ( 7 of 10 sessions above chance). It is possible that we would have seen an impairment in the hippocampal group with a larger sample, with longer delays, or with extended training, but the results of experiment 4 , although preliminary, suggest that such differences might be small.

\section{DISCUSSION}

Rats with hippocampal lesions failed to search at the goal. Because all animals passed this area regardless of whether they were able to compute an efficient trajectory, our findings suggest that the hippocampus is necessary for an animal to recognize the goal location and terminate its search upon arrival.
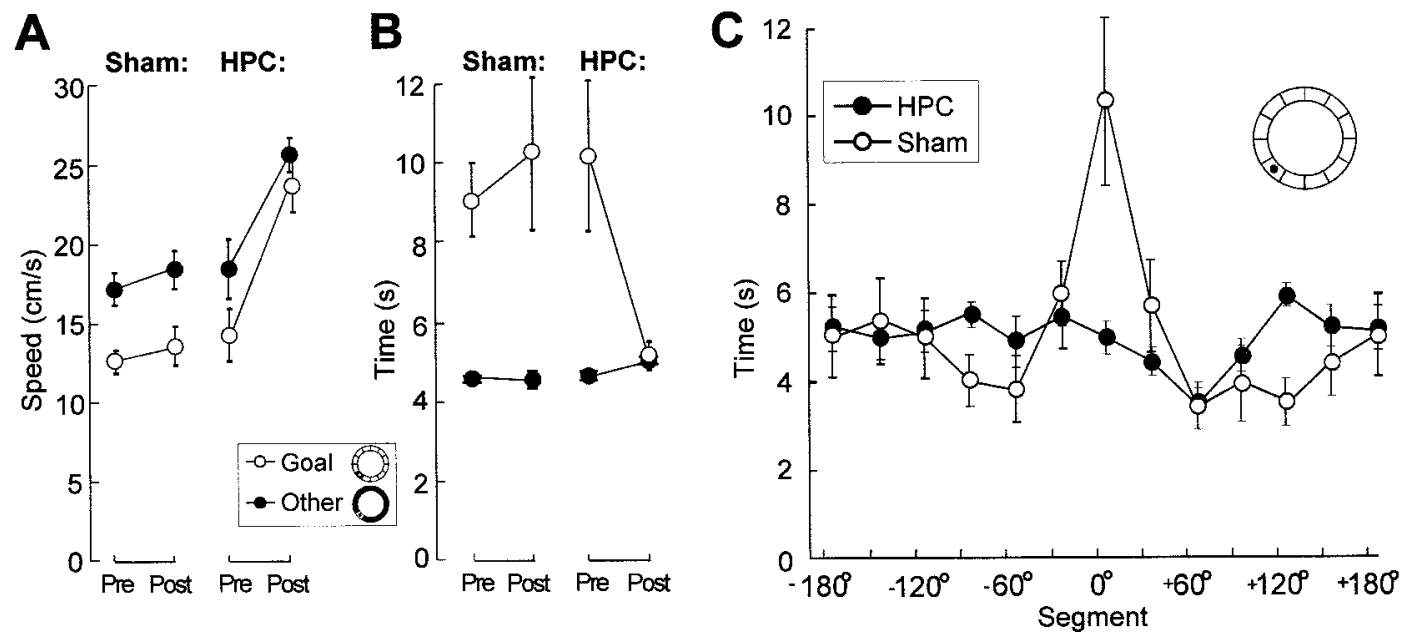

Figure 7. Effect of hippocampal lesions when the task was acquired before surgery. $(A, B)$. Speed $(A)$ and dwell time $(B)$ in the goal segment $\left(30^{\circ}\right)$ and the other segments (remaining $30^{\circ}$ ) before surgery (Pre) and $6 \mathrm{~d}$ after surgery (Post). Values are means \pm SEM. Only the sham-operated rats maintained their preference for the platform segment. Rats with lesions of the hippocampus $(H P C)$ failed to differentiate between target and nontarget segments. $C$, Dwell time (means $\pm \mathrm{SEM}$ ) in each of $1230^{\circ}$ segments of the annular corridor (inset) on the postoperative retention test. The platform segment is defined as $0^{\circ}$. 


\section{Did the animals have a memory deficit?}

The undifferentiated behavior of the hippocampal group does not necessarily imply that spatial memory was disrupted. Impaired performance after hippocampal ablation could reflect an inability to terminate thigmotactic behavior or, more generally, a failure to efficiently alter response strategies (Day et al., 1999). Hyperactivity and poor switching between motor programs could in principle account for the maintenance of high speed in the goal segment in rats with hippocampal lesions. However, when a visible platform was made available behind a small hole in the inner corridor wall, both lesioned and unlesioned rats slowed down, turned, swam through the door, and climbed the platform. Thus, they could stop when they knew where the platform was, suggesting that the lesion disrupted goal recognition rather than motor control.

\section{Hippocampal involvement in recognition of the goal location}

Most previous experiments are neutral as to whether hippocampal lesions compromise the ability to use spatial information to get to a goal, or the ability to recognize locations on arrival, or both. Rats with hippocampal lesions take indirect and apparently random routes toward the goal location (Morris et al., 1982, 1990; Eichenbaum et al., 1990), but if image recognition is a prerequisite for computing trajectories (Benhamou et al., 1995; Brown and Sharp, 1995; Reid and Staddon, 1998), this impairment could result from poor place recognition rather than poor trajectory planning. In the present task, inability to select an appropriate direction would not normally prevent the animals from entering the platform area. Thus, the failure to slow down over the platform in the hippocampal group probably reflected a failure in identifying this place as the target site. Our results do not establish whether the hippocampus is necessary also for computing trajectories between places, but the fact that firing in many place cells is influenced by the past or future path of the animal (Frank et al., 2000; Wood et al., 2000) suggests so.

A few previous studies have dissociated trajectory planning and goal recognition by simplified and extended training. After pretraining with a visible target in the water maze, rats with hippocampal lesions took circuitous routes to the platform but did slow down once they reached the goal region, indicating that they recognized the area but did not know how to get there (Whishaw et al., 1995; Whishaw and Jarrard, 1996). Similar results were obtained in a spatial odor discrimination task, in which hippocampal-lesioned rats failed to learn which cups to approach, but nonetheless refrained from digging for reward when they reached the wrong cup (Dudchenko et al., 2000). A different pattern appeared when rats with hippocampal damage started from a constant position in the water maze (Eichenbaum et al., 1990) or had an escape platform that initially occupied nearly the entire pool and then became progressively smaller (Day et al., 1999). These animals headed correctly toward the hidden target but failed to slow down and turn when they missed the target. Their impairment at the goal location was similar to the one seen here.

Why do these findings diverge? The earlier studies, unlike the present one, were characterized by explicit shaping of the escape behavior. Task demands were increased progressively, by either starting with a visible platform or reducing its size. Under these conditions, all animals, including those with lesions, performed at a low error rate during the initial trials. Human amnesics benefit substantially from such "errorless" training and are able to learn, as well as remember, some new semantic information when competing inappropriate responses are eliminated (Baddeley and Wilson, 1994). Such error prevention may account for the residual spatial learning capacity of hippocampal-lesioned animals, too. Whether the rats improve most on trajectory planning or goal recognition might depend on the exact training protocol.

The robustness of the recognition impairment in the present study may also reflect the fact that the rat had to choose between two responses at the goal location, slowing down and swimming on, with the appropriate decision depending on the animal's previous behavior during the trial. A similar decision was not required in the cued task. The choice requirement may have added to the impairment of the hippocampal group but was probably not the primary cause. If the rats knew the location of the goal but not whether they had already been there, they would likely have reduced their speed during each passage. However, animals with hippocampal lesions never slowed down, suggesting that recognition was disrupted specifically.

\section{What type of recognition memory was involved?}

Did the annular task measure recognition memory? Because performance requires that stimuli around the platform be matched against corresponding stimuli in the rat's memory, we tested a form of recognition. However, there are at least two types of recognition memory, a fast and familiarity-based recognition process that is spared in amnesia, and a slower identification process that is impaired in amnesia (Huppert and Piercy, 1976, 1978; Hintzman and Curran, 1994). When an animal slowed down over the platform in the annular corridor, it could not do so only by judging the familiarity or recency of specific landmarks. Because the rats swam in laps, they were exposed to all segments of the corridor several times in each trial during training, and the various regions of the apparatus were probably soon indistinguishable in terms of familiarity. To be able to slow down over the platform, they had to know that they were about to hit the hidden target. Termination of search behavior at the goal position therefore involves an element of associative recollection or recall and may thus rely on different brain structures than pure familiarity or recency judgments (Eichenbaum et al., 1994; Steckler et al., 1998; Aggleton and Brown, 1999). Accordingly, although the hippocampus may be instrumental in identifying the platform site as the goal, other circuits may, in principle, be sufficient for nonnavigational spatial recognition, such as tested in spatial delayed comparison tests.

Is the hippocampus necessary only for spatial types of recognition memory? There is evidence suggesting that hippocampal regions are active during discrimination between locations or arrangements of items but not when single items are to be recognized (Mumby et al., 1992; Gaffan, 1994; Ennaceur et al., 1996; Wan et al., 1999; Brown and Aggleton, 2001). The present results are consistent with this distinction, showing that hippocampal lesions disrupt recognition of spatial location but not necessarily recognition of single nonspatial items. However, single-item recognition is sometimes attenuated, particularly at long sample-test delays (Alvarez et al., 1995; Reed and Squire, 1997; Beason-Held et al., 1999; Clark et al., 2000; Stark and Squire, 2000), and a major task is to determine the exact conditions under which impairment occurs. One critical determinant may be whether recognition is accompanied by recall of features of the original encoding context (Huppert and Piercy, 1976, 1978; Eldridge et al., 2000). This additional element of associative recollection or cued recall may be what distinguishes perfor- 
mance in the annular corridor, and possibly in some spatial delayed comparison tasks, from hippocampal-independent tasks that can be solved purely by a nonassociative familiarity judgment.

\section{Image recognition outside the goal area}

Our results do not establish whether the hippocampus has a special function in recognition of goal locations or is necessary for image recognition also at earlier decision points along the animal's trajectory. The task taxed recognition of the goal location, but it is certainly possible that the identification of other locations was equally disrupted.

If the hippocampus contributes specifically to goal recognition, this might be expressed in the firing correlates of individual hippocampal neurons. It has been reported that some hippocampal neurons fire when animals approach or arrive at a goal, regardless of the goal's location (Eichenbaum et al., 1987; Breese et al., 1989; Gothard et al., 1996), but it remains to be determined what is signaled by such neurons. Hippocampal place fields can follow local landmarks even when these are not goals (O'Keefe and Speakman, 1987; Hetherington and Shapiro, 1997; Wood et al., 1999), suggesting that it may be sensory characteristics of the goal that provide the relevant input to the "goal cells" rather than its incentive value (Gothard et al., 1996). Goal-related activity has so far not been dissociated from sensory features (Speakman and O'Keefe, 1990). Thus, either the number of hippocampal cells with specific goal-recognition activity is small, or such activity is not expressed by a frequency code, or goal cells, if they exist, are located outside the hippocampus. If the latter is true, the failure to slow down in the goal segment after lesions of the hippocampus may perhaps represent a general impairment in recognition of spatial images that impedes the animal along the entire trajectory from start to goal.

\section{REFERENCES}

Aggleton JP, Brown MW (1999) Episodic memory, amnesia and the hippocampal-anterior thalamic axis. Behav Brain Sci 22:425-489.

Alvarez P, Zola-Morgan S, Squire LR (1995) Damage limited to the hippocampal region produces long-lasting memory impairment in monkeys. J Neurosci 15:3796-3807.

Baddeley A, Wilson BA (1994) When implicit learning fails: amnesia and the problem of error elimination. Neuropsychologia 32:53-68.

Beason-Held LL, Rosene DL, Killiany RJ, Moss MB (1999) Hippocampal formation lesions produce memory impairment in the rhesus monkey. Hippocampus 9:562-574.

Benhamou S, Bovet P, Poucet B (1995) A model for place navigation in mammals. J Theor Biol 173:163-178.

Bontempi B, Laurent-Demir C, Destrade C, Jaffard R (1999) Timedependent reorganization of brain circuitry underlying long-term memory storage. Nature 400:671-675.

Breese CR, Hampson RE, Deadwyler SA (1989) Hippocampal place cells: stereotypy and plasticity. J Neurosci 9:1097-1111.

Brown MA, Sharp PE (1995) Simulation of spatial learning in the Morris water maze by a neural network model of the hippocampal formation and nucleus accumbens. Hippocampus 5:171-188.

Brown MW, Aggleton JP (2001) Recognition memory: what are the roles of the perirhinal cortex and hippocampus? Nat Rev Neurosci 2:51-61.

Cheng K (2000) How honeybees find a place: lessons from a simple mind. Anim Learn Behav 28:1-15.

Clark RE, Zola SM, Squire LR (2000) Impaired recognition memory in rats after damage to the hippocampus. J Neurosci 20:8853-8860.

Day LB, Weisand M, Sutherland RJ, Schallert T (1999) The hippocampus is not necessary for a place response but may be necessary for pliancy. Behav Neurosci 113:914-924.

Dudchenko PA, Wood ER, Eichenbaum H (2000) Neurotoxic hippocampal lesions have no effect on odor span and little effect on odor recognition memory but produce significant impairments on spatial span, recognition, and alternation. J Neurosci 20:2964-2977.

Eichenbaum H, Kuperstein M, Fagan A, Nagode J (1987) Cue-sampling and goal-approach correlates of hippocampal unit activity in rats performing an odour-discrimination task. J Neurosci 7:716-732.
Eichenbaum H, Stewart C, Morris RGM (1990) Hippocampal representation in place learning. J Neurosci 10:3531-3542.

Eichenbaum H, Otto T, Cohen NJ (1994) Two functional components of the hippocampal memory system. Behav Brain Sci 17:449-518.

Eldridge LL, Knowlton BJ, Furmanski CS, Bookheimer SY, Engel SA (2000) Remembering episodes: a selective role for the hippocampus during retrieval. Nat Neurosci 3:1149-1152.

Ennaceur A, Neave N, Aggleton JP (1996) Neurotoxic lesions of the perirhinal cortex do not mimic the behavioural effects of fornix transection in the rat. Behav Brain Res 80:9-25.

Frank LM, Brown EN, Wilson M (2000) Trajectory encoding in the hippocampus and entorhinal cortex. Neuron 27:169-178.

Gaffan D (1994) Scene-specific memory for objects: a model of episodic memory impairment in monkeys with fornix transection. J Cognit Neurosci 6:305-320.

Gothard KM, Skaggs WE, Moore KM, McNaughton BL (1996) Binding of hippocampal CA1 neural activity to multiple reference frames in a landmark-based navigation task. J Neurosci 16:823-835.

Hetherington PA, Shapiro ML (1997) Hippocampal place fields are altered by the removal of single visual cues in a distance-dependent manner. Behav Neurosci 111:20-34.

Hintzman DL, Curran T (1994) Retrieval dynamics of recognition and frequency judgments: evidence for separate processes of familiarity and recall. J Mem Lang 33:1-18.

Huppert FA, Piercy M (1976) Recognition memory in amnesic patients: effect of temporal context and familiarity of material. Cortex 12:3-20.

Huppert FA, Piercy M (1978) The role of trace strength in recency and frequency judgements by amnesic and control subjects. Q J Exp Psychol 30:347-354.

Jarrard LE (1978) Selective hippocampal lesions: differential effects on performance by rats of a spatial task with preoperative versus postoperative training. J Comp Physiol Psychol 92:1119-1127.

Jarrard LE (1989) On the use of ibotenic acid to lesion selectively different components of the hippocampal formation. J Neurosci Methods 29:251-259.

Maguire EA, Frackowiak RSJ, Frith CD (1997) Recalling routes around London: activation of the right hippocampus in taxi drivers. J Neurosci 17:7103-7110.

Maguire EA, Burgess N, Donnett JG, Frackowiak RS, Frith CD, O'Keefe J (1998) Knowing where and getting there: a human navigation network. Science 280:921-924.

Morris RGM, Garrud P, Rawlins JNP, O'Keefe J (1982) Place navigation impaired in rats with hippocampal lesions. Nature 297:681-683.

Morris RGM, Schenk F, Tweedie F, Jarrard LE (1990) Ibotenate lesions of hippocampus and/or subiculum: dissociating components of allocentric spatial learning. Eur J Neurosci 2:1016-1028.

Moser MB, Moser EI (1998) Distributed encoding and retrieval of spatial memory in the hippocampus. J Neurosci 18:7535-7542.

Muller RU, Kubie JL, Ranck Jr JB (1987) Spatial firing patterns of hippocampal complex-spike cells in a fixed environment. J Neurosci 7:1935-1950.

Mumby DG, Wood ER, Pinel JPJ (1992) Object-recognition memory is only mildly impaired in rats with lesions of the hippocampus and amygdala. Psychobiology 20:18-27.

Murray EA, Mishkin M (1998) Object recognition and location memory in monkeys with excitotoxic lesions of the amygdala and hippocampus. J Neurosci 18:6568-6582.

Nadel L (1991) The hippocampus and space revisited. Hippocampus 1:221-229.

O'Keefe J, Burgess N (1996) Geometric determinants of the place fields of hippocampal neurons. Nature 381:425-428.

O'Keefe J, Dostrovsky J (1971) The hippocampus as a spatial map. Preliminary evidence from unit activity in the freely moving rat. Brain Res 34:171-175

O'Keefe J, Nadel L (1978) The hippocampus as a cognitive map. Oxford: Clarendon.

O'Keefe J, Speakman A (1987) Single unit activity in the hippocampus during a spatial memory task. Exp Brain Res 68:1-27.

O'Keefe J, Nadel L, Keightley S, Kill D (1975) Fornix lesions selectively abolish place learning in the rat. Exp Neurol 48:152-166.

Olton DS, Walker JA, Gage FH (1978) Hippocampal connections and spatial discrimination. Brain Res 139:295-308.

Quirk GJ, Muller RU, Kubie JL (1990) The firing of hippocampal place cells in the dark depends on the rat's recent experience. J Neurosci 10:2008-2017.

Reed JM, Squire LR (1997) Impaired recognition memory in patients with lesions limited to the hippocampal formation. Behav Neurosci 111:667-675.

Reid AK, Staddon JER (1998) A dynamic route finder for the cognitive map. Psychol Rev 105:585-601.

Speakman A, O'Keefe J (1990) Hippocampal complex spike cells do not change their place fields if the goal is moved within a cue-controlled environment. Eur J Neurosci 2:544-555.

Squire LR (1992) Memory and the hippocampus: a synthesis from findings with rats, monkeys, and humans. Psychol Rev 99:195-231. 
Stark CE, Squire LR (2000) Functional magnetic resonance imaging (fMRI) activity in the hippocampal region during recognition memory. J Neurosci 20:7776-7781.

Steckler T, Drinkenburg WH, Sahgal A, Aggleton JP (1998) Recognition memory in rats. II. Neuroanatomical substrates. Prog Neurobiol 54:313-332.

Sutherland RJ, Whishaw IQ, Kolb B (1983) A behavioural analysis of spatial localization following electrolytic, kainate- or colchicineinduced damage to the hippocampal formation in the rat. Behav Brain Res 7:133-153.

Wan H, Aggleton JP, Brown MW (1999) Different contributions of the hippocampus and perirhinal cortex to recognition memory. J Neurosci 19:1142-1148.
Whishaw IQ, Jarrard LE (1996) Evidence for extrahippocampal involvement in place learning and hippocampal involvement in path integration. Hippocampus 6:513-524.

Whishaw IQ, Cassel JC, Jarrard LE (1995) Rats with fimbria-fornix lesions display a place response in a swimming pool: a dissociation between getting there and knowing where. J Neurosci 15:5779-5788.

Wilson MA, McNaughton BL (1993) Dynamics of the hippocampal ensemble code for space. Science 261:1055-1058.

Wood ER, Dudchenko PA, Eichenbaum H (1999) The global record of memory in hippocampal neuronal activity. Nature 397:613-616.

Wood ER, Dudchenko PA, Robitsek RJ, Eichenbaum H (2000) Hippocampal neurons encode information about different types of memory episodes occurring in the same location. Neuron 27:623-633. 